\title{
Perbandingan Kemampuan Pelepasan Panas Pada Alat Penukar Panas Radiator Straight Fin Jenis Circular Cylinder Tube Dengan Flat Tube
}

\author{
Nuzul Hidayat ${ }^{1^{*}}$, Ahmad Arif $^{1}$, Martias $^{1}$ \\ ${ }^{1}$ Jurusan Teknik Otomotif, Fakultas Teknik, UniversitasNegeri Padang \\ *Corresponding author, e-mail: nuzulhidayat@ft.unp.ac.id
}

\begin{abstract}
Abstrak - Mesin mobil pasti menghasilkan panas akibat pembakaran dari bahan bakar. Disatu sisi panas ini menguntungkan jika dikendalikan dengan baik yaitu antara $70^{\circ} \mathrm{C}$ $9^{\circ} \mathrm{C}$ namun sebaliknya jika panas ini tidak terkendali maka akan menimbulkan masalah. Apabila temperatur ini dibiarkan maka akan menyebabkan mesin menjadi overheating sehingga bisa membuat kerusakan pada komponen-komponen mesin. Dalam hal ini perlu solusi untuk menjaga mesin tetap dalam tempertur kerja dengan cara melengkapi mesin dengan sistem pendingin. Disamping itu perkembangan dalam teknologi desain radiator saat ini sudah menciptakan radiator memiliki banya varian dan bentuk, dan yang paling umum berkembang adalah model straight fin dengan flat tube dan circular cylinder tube. Kondisi ini membuat peneliti tertarik desain yang mana yang paling bagus dalam pelepasan panas untuk mendinginkan air pendingin. Untuk itu perlu upaya untuk mengetahui kemampuan radiator secara jelas agar ini dapat membantu dalam pemilihan komponen pada sebuah mobil sehingga mesin tidak mengalami overheating atau mesin tetap menjaga temperatur kerjanya. Penelitian ini dilakukan secara eksperimental yaitu dengan menvariasikan tipe radiator dan putaran mesin serta memberikan perlakuan yang sama terhadap benda uji. Hasil penelitian menunjukan bahwa dari semua variasi kecepatan jenis radiator yang memiliki kemampuan pelepasan panas yang baik adalah tipe flat tube dengan nilai efektifitas 0.593 dengan variasi kecepatan aliran $3.52 \mathrm{~m} / \mathrm{s}$ dan $120 \mathrm{~s}$. Dapat disimpulkan dari penelitian adalah radiator tipe flat tube memiliki pelepasan panas lebih baik dari tipe circular cylinder tube.
\end{abstract}

Kata Kunci : Over heating, radiator straight fin, flat tube, circular cylinder tube.

\begin{abstract}
On the one hand, this heat is beneficial if it is controlled properly, which is between $70^{\circ} \mathrm{C}-90^{\circ} \mathrm{C}$ but on the other hand if this heat is not controlled it will cause problems. If this temperature is allowed it will cause the engine to become overheating so that it can make damage to the engine components. In this case, a solution is needed to keep the engine in the working temperature by completing the engine with a cooling system. Besides that, developments in radiator design technology have now created radiators with many variants and shapes, and the most common is the straight fin model with a flat tube and circular cylinder tube. This condition makes researchers interested in the design which is the best in the release of heat to cool the cooling water. For this reason, efforts need to be made to find out the radiator's capabilities clearly so that this can help in the selection of components in a car so that the engine does not experience overheating or the engine keeps its working temperature. This research was carried out experimentally by varying the radiator type and engine speed and giving the same treatment to the test object. The results showed that of all variations in the type of radiator speed that have good heat release ability are flat tube types with an effectiveness value of 0.593 with variations in flow velocity of $3.52 \mathrm{~m} / \mathrm{s}$ and time of $120 \mathrm{~s}$. It can be concluded from the study that the flat tube type radiator has a heat release better than the circular cylinder tube type.
\end{abstract}

Keywords : Over heating, radiator straight fin, flat tube, circular cylinder tube.

This is an open access article distributed under the Creative Commons 4.0 Attribution License 


\section{Pendahuluan}

Sistem pendingin merupakan bagian utama dalam sebuah engine yang berfungsi untuk menjaga kondisi mesin agar tetap berada pada temperatur kerja sebesar $80^{\circ} \mathrm{C}$. Untuk mempertahankan kondisi tersebut dibutuhkan kerja yang optimal dari sistem pendingin. Salah satu komponen sistem pendingin yang penting adalah radiator. Radiator merupakan suatu alat yang berfungsi sabagai penukar panas. Panas ini diperoleh dari hasil pembakaran sebuah engine yang yang di transfer melalui fluida pendingin ke radiator. Kemudian panas pada radiator dipindahkan ke lingkungan (ambient) melalui sirip-sirip raditor.

Selain merekayasa dari sisi posisi dan udara pendingin akhir-akhir ini juga berkembang untuk radiator mobil jenis straight fin tapi memiliki jenis circular cylinder tube. Jenis ini termasuk produk baru, sebagian masyarakat awam tidak paham dan mengetahui perbedaan model akan mempengaruhi kemampuan pendinginan dari air pending pada mobil. Perubahan yang terjadi akan bisa berdampak baik atau sebalikinya karena terdapatnya ketidak sesuai model terhadap kebutuhan pendinginan

Dalam perkembangannya radiator mengalami banyak perubahan, baik dari sisi material, kontruksi maupun desain dasarnya sebagai alat penukar panas. Pada penggunannya dilapangan yang paling terlihat adalah dari kontruksi pipa laluan air pendingin yang jauh berbeda terutama pada mesin Toyota Kijang seri $5 \mathrm{~K}$. Model yang paling umum ada 2 model laluan air pendingin diantranya jenis flat tube dan circular cylinder tube.Selain merekayasa dari sisi posisi dan udara pendingin akhir-akhir ini juga berkembang untuk radiator mobil jenis straight fin tapi memiliki jenis circular cylinder tube. Jenis ini termasuk produk baru, sebagian masyarakat awam tidak paham dan mengetahui perbedaan model akan mempengaruhi kemampuan pendinginan dari air pendingin pada mobil. Perubahan yang terjadi akan bisa berdampak baik atau sebaliknya karena terdapatnya ketidak sesuai model terhadap kebutuhan pendinginan.

Banyak studi yang sudah dilakukan dalam optimasi penggunaan radiator yang bertujuan mendapatkan penurunan maksimal temperatur air pendinginan. Optimasi pengunaan radiator yang dilakukan dengan merekayasa dudukan radiator pada mesin Toyota kijang seri $5 \mathrm{~K}$ sehingga bisa diatur sudut serang udara pendingin dari $5^{0}-20^{0}$ terhadap arah sudut serang udara pendingin, hasilnya didapatkan efektifitas pendinginan yang paling baik pada posisi $5^{0}$ dari semua variasi dan dibandingkan dengan posisi standar [1].

Selain itu penelitian telah dilakukan untuk meningkatkan efektivitas kerja dari radiator. Penelitian dengan menganalisa pelepasan panas pada pendinginan yang terjadi pada radiator yang terdapat dimotor bakar otto pada setiap putaran mesin dengan metode perpindahan NTUefektivitas penukar kalor dan dia menyimpulkan bahwa nilai $\mathrm{C}_{\text {min }} / \mathrm{C}_{\text {maks }}$ sebesar 0,5 , NTU sebesar 1,3 dan efektivitas sebesar 0,65 serta perpindahan kalor secara keseluruhan sebesar 5,187 watt [2]. Penelitian dengan optimasi desain fan pendingin terhadap pendinginan radiator menggunakan metode eksperimen dengan memvariasikan bentuk fan (jumlah sudu: 5-7 buah dan sudut sudu: $30^{\circ}$ dan $\left.60^{\circ}\right)$ dan jarak pemasangan sudu ke radiator $(1,5-$ $2,5 \mathrm{~cm}$ ), dan dia menyimpulkan bahwa jumlah sudu dan jarak fan terhadap radiator sangat berpengaruh terhadap pendinginan air radiator[3].

Penelitian dengan menganalisa debit aliran cairan pendingin terhadap efektivitas radiator pada mesin mobil Mazda menggunakan metode eksperimen dengan memvariasikan waktu penahanan (holdingtime) 1-30 menit interval 5 menit dan putaran mesin 1000-1400 rpm interval $100 \mathrm{rpm}$, dia menyimpulkan bahwa jumlah aliran air berpengaruh terhadap nilai efektivitas radiator waktu penahanan 30 menit terjadi peningkatan nilai efektivitas yang seimbang, sesuai dengan kenaikan jumlah aliran air, ini menunjukkan adanya kestabilan nilai efektifitas radiator [4].Penelitian pengaruh temperatur cairan pendingin terhadap unjuk kerja perpindahan panas dan penurunan tekanan radiator otomotif menggunakan metode eksperimen dengan memvariasikan temperatur cairan pendingin yang masuk ke radiator $\left(60{ }^{\circ} \mathrm{C}\right.$ sampai $90{ }^{\circ} \mathrm{C}$ dengan interval $10{ }^{\circ} \mathrm{C}$ ) dan debit aliran (30 sampai $45 \mathrm{lpm}$ dengan interval $5 \mathrm{lpm}$ ), dan dia menyimpulkan bahwa temperatur cairan pendingin masuk $90{ }^{\circ} \mathrm{C}$ dan debit $45 \mathrm{lpm}$ menghasilkan nilai laju perpindahan panas dan koefisien perpindahan panas secara konveksi di sisi cairan pendingin terbesar yaitu 23475 watt dan $8263,75 \mathrm{~W} / \mathrm{m} 2{ }^{\circ} \mathrm{C}$. Dan nilai penurunan tekanan terkecil sebesar 22405,9 Pa [5].

Dari latar belakang di atas dapat dipahami bahwa radiator berfungsi sebagai alat penukar panas yang akan mempengaruhi performa mesin. Sejauh ini penelitian banyak menfokuskan pada pengaturan jarak posisi radiator, kecepatan udara pembuang panas, volume air radiator, temperatur coolant dan debit aliran serta perubahan geometri 
sirip radiator serta bentuk tube tempat air pendingin didinginkan. Oleh karena itu peniliti mencoba melakukan penelitian dengan merubah membandingkan radiator straight fin jenis flat tube dengan circular cylinder tube dengan tujuan agar mendapatkan efektivitas radiator yang paling baik diantara keduanya.

\section{Studi Pustaka}

\section{Perpindahan Panas}

Perpindahan panas adalah perpindahan energi dalam bentuk panas karena adanya perbedaan suhu/temperature gradient. Secara alami perpindahan panas terjadi ke arah suhu yang rendah dan apabila semakin besar temperature gradient maka semakin besar panas yang dipindahkan. Perpindahan panas berlangsung dengan beberapa cara. Perpindahan kalor secara konduksi adalah perpindahan kalor melalui perantara tidak dikuti oleh perpindahan zat tersebut. Laju perpindahan panas secara konduksi yaitu berbanding dengan gradien suhu normal sesuai dengan persamaan dibawah ini:

Persamaan perpindahan panas secara konduksi:

$$
\begin{aligned}
& q=-k A \frac{\partial \mathrm{T}}{\partial x} \\
& \text { Dimana } \\
& q=\text { laju perpindahan kalor }(\mathrm{kj} / \mathrm{det} \text { atau watt) } \\
& k=\text { konduktivitas kalor material }(\mathrm{W} / \mathrm{mK}) \\
& A=\text { luas penampang }\left(\mathrm{m}^{2}\right) \\
& \partial \mathrm{T}=\text { Selisih suhu }(\mathrm{K}) \\
& d T / d x=\text { Selisih jarak }(\mathrm{m})
\end{aligned}
$$

$d T / d x=$ gradient temperatur kearah perpindahan kalor konstanta positif' $k$ " disebut konduktifitas atau kehantaran termal benda itu, sedangkan tanda minus disisipkan agar memenuhi hukum kedua termodinamika, yaitu bahwa kalor mengalir ketempat yang lebih rendah dalam skala temperatur [6].

Perpindahanpanas secara konveksimerupakan perpindahan panas suatu zat yang diikuti dengan perpindahan zat tersebut.

Laju perpindahan panas pada beda suhu tertentu dapat dihitung dengan persamaan

$$
q=\underset{\text { dimana }}{-h A\left(T_{w}-T_{\infty}\right.}
$$

$q=$ Laju perpindahan panas ( $\mathrm{kj} / \mathrm{det}$ atau $\mathrm{W}$ )

$h=$ Koefisien perpindahan panas konveksi ( W

$$
/ \mathrm{m}^{2} \mathrm{~K} \text { ) }
$$

$A=$ Luas bidang permukaan perpindahaan panas

$\left(\mathrm{m}^{2}\right)$

$T_{w}=$ suhu dinding $(\mathrm{k})$

$T_{\infty}=$ suhusekeliling $(\mathrm{K})$
Tanda minus (-) digunakan untuk memenuhi hukum II thermodinamika, sedangkan panas yang dipindahkan selalu mempunyai tanda positif (+). Persamaan (2.2) mendefinisikan tahanan panas terhadap konveksi. Koefisien pindah panas permukaan $h$, bukanlah suatu sifat zat, akan tetapi menyatakan besarnya laju pindah panas di daerah dekat pada permukaan itu.

Perpindahan kalor secara konveksi paksa banyak digunakan pada sistem pendingin mesin atau yang dikenal dengan istilah radiator. Sistem pendingin ini digunakan pada mesin mobil.Adapun aliran yang terjadi dalam pipa adalah fluida yang dibatasi oleh suatu permukaan. Sehingga lapisan batas tidak dapat berkembang secara bebas seperti halnya pada aliran luar. Sebagai gambaran adalah fenomena perpindahan panas aliran di dalam pipa yang dinyatakan sebagai:

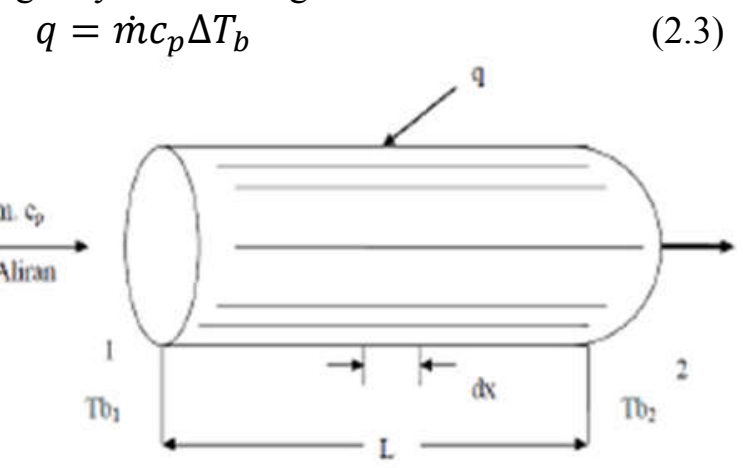

Gambar 1.Perpindahan panas secara konveksi paksa

Perpindahan kalor tanpa zat perantara merupakan radiasi. Radiasi adalah perpindahan panas tanpa zat perantara. Radiasi biasanya disertai cahaya. Untuk menentukan besarnya energi adalah $\left.q^{\prime \prime}=\varepsilon \sigma T_{s}^{4}\right)$

Dimana

$q^{\prime \prime}=$ laju perpindahan panas $(\mathrm{W})$

$\sigma=$ konstanta boltzman $(5,669.10-8 \mathrm{~W} / \mathrm{m} 2 . \mathrm{K} 4)$

$\varepsilon=$ emissivity $(0<\varepsilon<1)$

$T_{S}=$ suhu absolut benda $(0 \mathrm{C})$

\section{Alat Penukar Panas (Heat Exchanger)}

Alat penukar panas (heat exchanger) adalah suatu alat yang digunakan untuk melepaskan panas antara dua buah fluida yang memiliki perbedaan suhu yaitu fluida yang bersuhu tinggi ke fluida yang bersuhu rendah. Salah satu aplikasinya paling banyak digunakan pada mobil sebagai sistem pendinginan pada mesin untuk mencegah overheating. 
Radiator adalah sebuah alat penukar panas yang berfungsi memindahkan energi panas dari satu medium ke medium lainnya.Radiator terdapat pada bagian depan kendaraan yang dilengkapi dengan coling fan. Kontruksi dari radiator sangat membantu mempercepat proses pelapasan panas yaitu dengan dilengkapi fin (sirip-sirip) dan bentuk pipa yang pipih atau jenis (flat tube).

Pada perkembangannya teknologi pembuatan radiator terus berjalan baik dari sisi material, kontruksi dan desain radiator tersebut. Namun perubahan yang paling signifikan pada radiator mobil Toyota Kijang seri $5 \mathrm{~K}$ adalah tube atau pipa laluan air radiator model flat tube yang paling umum sekarang ada juga yang jenis circular cylinder tube. Kondisi ini membuat perubahan yang signifikan baik dari sisi kontruksi maupun kemampuan pelepasan panas dari radiator tersebut. Perubahan dari tube tersebut maka akan mempengaruhi luas bidang pelapasan panas dan akan secara otomatis akan mempengaruhi efektivitas radiator.

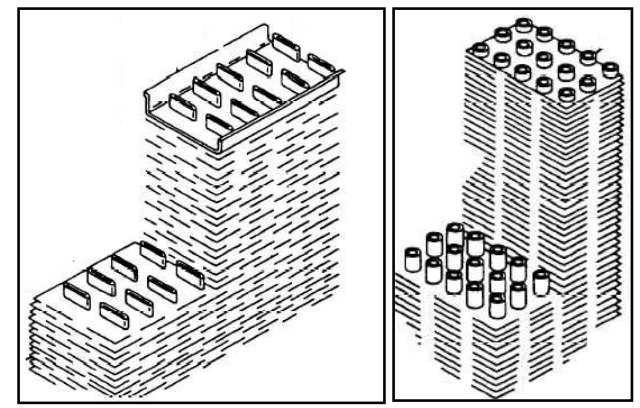

Gambar 2. Radiator straight finjenis flat tube dan circular cylinder tube

\section{Perpindahan Panas Radiator}

Fungsi radiator adalah melepas panas, maka dalam pembuatannya dipilih radiator yang memiliki konduktivitas termal yang tinggi, yaitu mampu menghantarkan panas yang baik seperti tembaga dan kuningan. Panas yang dibuang oleh cairan pendingin dapat dihitung dengan menggunakan persamaan yaitu

$q=\dot{m} c_{p} \Delta T$

$q=\dot{m} c_{p} T_{2}-T_{1}$

dimana

$q \quad=$ laju perpindahan panas $(\mathrm{kJ} / \mathrm{det}$ atau $\mathrm{W})$

$m=$ massa laju aliran cairan pendingin $(\mathrm{kg} / \mathrm{s})$

$c_{p} \quad=$ kapasitas panas masuk $(\mathrm{J} / \mathrm{kgK})$

$T_{1}=$ Temperatur masuk $(\mathrm{K})$

$T_{2}=$ Temperatur keluar $(\mathrm{K})$

Dari persamaan tersebut maka kita bisa dapat menganalisis perpindahan panas pada sebuah radiator sebagai berikut [6]:
1. Jumlah panas yang dilepaskan oleh air

$$
q_{a}=\dot{m}_{a} c_{p} T_{a 1}-T_{a 2}
$$

dimana

$q_{a}=$ laju perpindahan panas yang dilepas air ( $\mathrm{kJ} /$ det atau $\mathrm{W}$ )

$m_{a}=$ massa laju air yang mengalir $(\mathrm{kg} / \mathrm{s})$

$c_{p}=$ kapasitas panas masuk $(\mathrm{J} / \mathrm{kgK})$

$T_{a 1}=$ Temperatur air masuk $(\mathrm{K})$

$T_{a 2}=$ Temperatur air keluar $(\mathrm{K})$

Sedangkan untuk menghitung massa air yang mengalir dapat menggunakan persamaan

$\dot{m}_{a}=\rho_{a} V_{a} A$

dimana

$\rho_{a}=$ massa jenis air $\left(\mathrm{kg} / \mathrm{m}^{3}\right)$

$V_{a}=$ kecepatan air masuk $(\mathrm{m} / \mathrm{s})$

$A=$ luas penampang saluran masuk $\left(\mathrm{m}^{2}\right)$

2. Jumlah panas oleh udara pendingin

$q_{u}=\dot{m}_{u} c_{p} T_{u 2}-T_{u 1}$

dimana

$q_{u}=$ Laju perpindahan panas yang diterima udara pendingin (Watt)

$\dot{m}_{u}=$ massa laju aliran udara yang mengalir $(\mathrm{kg} / \mathrm{s})$

$c_{p}=$ kapasitas panas masuk $(\mathrm{J} / \mathrm{kgK})$

$T_{u 1}=$ Temperatur udara keluar $(\mathrm{K})$

$T_{u 2}=$ Temperatur udara masuk $(\mathrm{K})$

Sedangkan untuk menghitung massa udara yang mengalir dapat menggunakan persamaan adalah

$\dot{m}_{u}=\rho_{u} V_{u} A$

dimana

$\rho_{u}=$ massa jenis udara $\left(\mathrm{kg} / \mathrm{m}^{3}\right)$

$V_{u}=$ kecepatan udara masuk $(\mathrm{m} / \mathrm{s})$

$A=$ luas penampang saluran masuk udara

\section{Efektivitas (kemampuan pemindahan panas)}

Efektivitas penukar panas adalah perbandingan antara laju perpindahan kalor yang sebenarnya dengan laju perpindahan kalor maksimum yang mungkin. Persamaannya dapat ditunjukan seperti berikut ini [6]:

$$
\begin{aligned}
& \varepsilon=\frac{q}{q_{\max }} \\
& \quad \text { dimana } \\
& q \quad \text { Perpindahan panas nyata }(\mathrm{W}) \\
& q_{\max }=\text { perpindahan panas maksimum yang } \\
& \quad \text { mungkin }(\mathrm{W})
\end{aligned}
$$

Untuk perpindahan panas yang sebenarnya (aktual) dapat dihitung dari energi yang dilepaskan oleh fluida panas atau energi yang diterima oleh fluida dingin untuk penukar panas aliran lawan arah.

$q=\dot{m}_{h} c_{h}\left(T_{h, \text { in }}-T_{h, \text { out }}\right)=\dot{m}_{c} c_{c}\left(T_{c, \text { out }}-T_{c, \text { in }}\right)$ (2.11) 
Dimana :

$\dot{m}_{h}=$ laju aliran fluida panas $(\mathrm{kg} / \mathrm{s})$

$\dot{m}_{c}=$ laju aliran fluida dingin $(\mathrm{kg} / \mathrm{s})$

$c_{h}=$ kapasitas panas fluida panas $(\mathrm{Kj} / \mathrm{kg} \mathrm{K})$

$c_{c}=$ kapasitas panas fluida dingin $(\mathrm{Kj} / \mathrm{kgK})$

$T_{h, i n}=$ Temperatur masuk fluida panas (K)

$T_{h, o u t}=$ Temperatur keluar fluida panas $(\mathrm{K})$

$T_{c, i n}=$ Temperatur masuk fluida dingin $(\mathrm{K})$

$T_{c, \text { out }}=$ Temperatur keluar fluida dingin (K)

Kapasitas panas setiap fluida dapat dihitung dengan persamaan:

$$
\begin{aligned}
C= & \dot{m} c_{p} \\
& \text { dimana } \\
\dot{m}= & \text { laju aliran fluida }(\mathrm{kg} / \mathrm{s}) \\
c_{p}= & \text { panas spesifik fluida }(\mathrm{Kj} / \mathrm{kg} \mathrm{K})
\end{aligned}
$$

Untuk menentukan perpindahan panas maksimum bagi penukar panas itu harus dipahami bahwa nilai maksimum akan didapat bila salah satu fluida mengalami perubahan temperatur sebesar beda temperatur maksimum yang terdapat dalam penukar panas itu, yaitu selisih temperatur masuk fluida panas dan fluida dingin. Fluida yang mungkin mengalami beda temperatur maksimum ini ialah yang laju aliran fluida dinginnya minimum, syarat keseimbangan energi bahwa energi yang diterima oleh fluida yang satu harus sama dengan energi yang dilepas oleh fluida yang lain. Jika fluida yang mengalami nilai laju alitan fluida dingannya lebih besar yang dibuat, maka mengalami beda temperatur yang lebih besar dari maksimum, dan ini tidak dimungkinkan. Jadi perpindahan panas maksimum yang mungkin dinyatakan sebagai :

$q_{\max }=\dot{m} c_{\min }\left(T_{h, \text { in }}-T_{c, \text { in }}\right)$

dimana, $c_{\min }$ merupakan kapasitas panas yang terkecil antara fluida dingin dan fluida panas. Jika $c_{h}=c_{\min }$ maka nilai efektivitas dapat tentukan menggunakan persamaan dibawah ini:

$\varepsilon=\frac{\dot{m}_{h} c_{h}\left(T_{h, \text { in }}-T_{h, \text { out }}\right)}{\dot{m} c_{\min }\left(T_{h, \text { in }}-T_{c, \text { in }}\right)}$

$\varepsilon=\frac{\left(T_{h, \text { in }}-T_{h, \text { out }}\right)}{\left(T_{h, \text { in }}-T_{c, \text { in }}\right)}$

Untuk $c_{c}=c_{\min }$, nilai efektivitas dapat dihitung menggunakan persamaan dibawah ini:

$$
\begin{aligned}
\varepsilon & =\frac{\dot{m}_{c} c_{c}\left(T_{c, \text { out }}-T_{c, \text { in }}\right)}{\dot{m} c_{\min }\left(T_{h, \text { in }}-T_{c, \text { in }}\right)} \\
\varepsilon & =\frac{\left(T_{c, \text { out }}-T_{c, \text { in }}\right)}{\left(T_{h, \text { in }}-T_{c, \text { in }}\right)}
\end{aligned}
$$

\section{METODE}

Penelitian ini dilakukan dengan menggunakan metode eksperimental. Pengujian dilakukan pada engine stand mobil Toyota Kijang seri mesin $5 \mathrm{~K}$ dengan model radiator straight finjenis flat tubedan circular cylinder tube.. Untuk memperoleh efektivitas radiator yang optimun dilakukan variasi radiator, kecepatan putaran mesin (low, midle dan high) dan juga dengan variasi waktu, kemudian dianalisis dengan menggunakan persamaan efektifitas $(\varepsilon)$ pada alat penukar panas dengan cara mengukur temperatur air pendingin dan udara pendingin.

Proses pemasangan radiator dan seluruh rangkaian pengujian dilakukan di Laboratorium Motor Bakar dan pengujian kendaraan Jurusan Teknik Otomotif Fakultas Teknik Universitas Negeri Padang. Penelitian ini dibagi atas dua kelompok, yaitu:

1. Kelompok kontrol adalah radiator jenis flat tube.

2. Kelompok uji adalah radiator circular cylinder tube.

Objek dalam penelitian ini sebagai berikut:

Radiator straigt fin, dengan spesifikasi:

Mesin : Kijang super 5k

Model fin : straight fin

Model Tube : flat tube dan circular cylinder tube

Type collant: water collant

Flow type : downflow

Pada gambar 3dan 4 di bawah merupakan skema radiator straight finjenis flat tube.

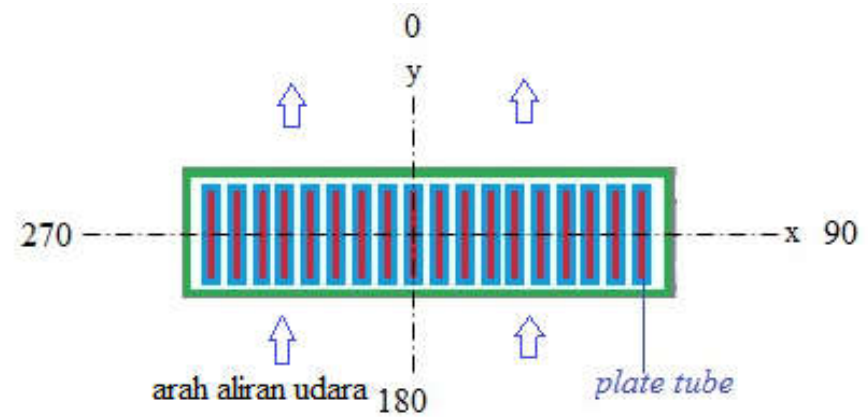

Gambar 3. Skema radiator straight finjenis flat tubepada pandangan atas

Adapun gambar 4 merupakan radiator straight finjenis circular cylinder tube. Adapun untuk skema apparatus experimental penelitian dapat dilihat pada gambar 5 . 
$0^{\circ}$

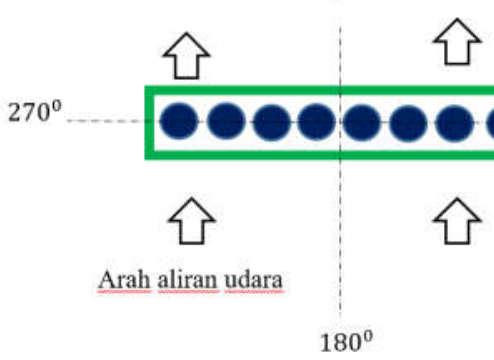

Gambar 4. Skema radiator straight fin dengan model circular cylinder tube pada pandangan atas

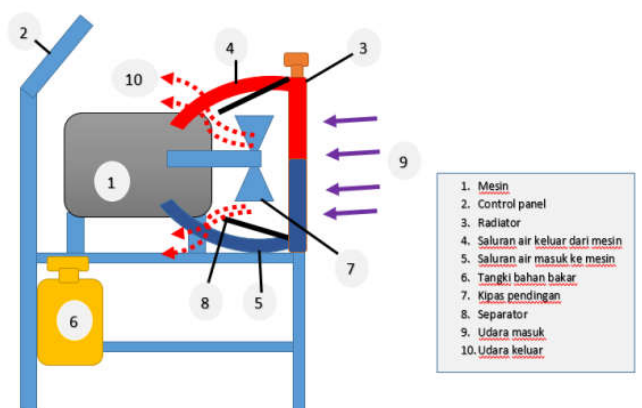

Gambar 5. Skema apparatus experimental penelitian

\section{HASIL DAN PEMbahasan}

Untuk melihat hasil yang telah dicapai, maka data yang sudah didapat akan di input kedalam tabel yang sudah di sediakan.

Efektifitas dengan variasi waktu dan kecepatan aliran udara pendingin. Dalam variasi ini didapat data yang ditampilkan pada tabel dibawah ini. Hasil ini pada tipe flat tube(FT)

Pada tabel 1, 2 dan 3 dapat didapat informasi bahwa tingkat pelepasan panas paling baik pada jenis radiator flate tube terdapat pada kecepatan aliran $3.52 \mathrm{~m} / \mathrm{s}$ dengan variasi waktu 120 detik yang memiliki nilai efektifitas sebesar 0.593. Ratarata pelepasan panas terjadi dengan nilai efektifitas antara 0.4- 0.5. Hal menarik juga terjadi bahwa dengan meningkatnya kecepatan aliran udara ternyata kemampuan radiator menurunkan temperatur air pendingin juga menurun akibat putaran kipas pendingin bergantung pada putaran mesin, sehingga temperatur mesin juga meningkat dan dipastikan temperatur air pendingin juga meningkat secara tidak langsung.

Sedangkan pada tabel 4, 5 dan 6 adalah hasil pengujian tipe circular cylinder tube(CCT) dengan variasi waktu dan kecepatan aliran udara pendingin
Tabel 1. Efektifitas radiator tipe flat tube kecepatan rendah dengan variasi waktu

\begin{tabular}{cccccccc}
\hline No & $\begin{array}{c}\text { Time } \\
(\mathbf{S})\end{array}$ & $\begin{array}{c}\text { Air } \\
\text { Velocity } \\
(\mathbf{m} / \mathbf{s})\end{array}$ & $\begin{array}{c}\text { water } \\
\text { in } \\
(\mathbf{C})\end{array}$ & $\begin{array}{c}\text { water } \\
\text { out } \\
(\mathbf{C})\end{array}$ & $\begin{array}{c}\text { Tair } \\
\text { in } \\
(\mathbf{C})\end{array}$ & $\begin{array}{c}\text { T air } \\
\text { out } \\
(\mathbf{C})\end{array}$ & $\begin{array}{c}\mathbf{E f e k} \\
\text { tivitas }\end{array}$ \\
\hline 1 & 120 & 3,52 & 59,30 & 57,50 & 31,30 & 47,90 & 0,593 \\
\hline 2 & 240 & 3,52 & 59,90 & 58,00 & 31,50 & 48,10 & 0,585 \\
\hline 3 & 360 & 3,52 & 59,80 & 57,70 & 31,30 & 47,90 & 0,582 \\
\hline 4 & 480 & 3,52 & 60,00 & 57,90 & 31,70 & 47,80 & 0,569 \\
\hline 5 & 600 & 3,52 & 60,10 & 58,20 & 31,40 & 48,20 & 0,585 \\
\hline
\end{tabular}

Tabel 2. Efektifitas radiator tipe flat tube kecepatan sedang dengan variasi waktu

\begin{tabular}{cccccccc}
\hline No & $\begin{array}{c}\text { Time } \\
(\mathbf{S})\end{array}$ & $\begin{array}{c}\text { Air } \\
\text { Velocity } \\
(\mathbf{m} / \mathbf{s})\end{array}$ & $\begin{array}{c}\text { water } \\
\text { in } \\
(\mathbf{C})\end{array}$ & $\begin{array}{c}\text { water } \\
\text { out } \\
(\mathbf{C})\end{array}$ & $\begin{array}{c}\text { Tair } \\
\text { in } \\
(\mathbf{C})\end{array}$ & $\begin{array}{c}\text { T air } \\
\text { out } \\
(\mathbf{C})\end{array}$ & $\begin{array}{c}\text { Efek } \\
\text { tivitas }\end{array}$ \\
\hline 1 & 120 & 6,07 & 59,60 & 57,90 & 33,00 & 47,40 & 0,541 \\
\hline 2 & 240 & 6,07 & 60,40 & 58,40 & 32,20 & 47,20 & 0,532 \\
\hline 3 & 360 & 6,07 & 60,30 & 58,70 & 31,50 & 47,50 & 0,556 \\
\hline 4 & 480 & 6,07 & 61,00 & 59,10 & 33,00 & 48,80 & 0,564 \\
\hline 5 & 600 & 6,07 & 60,80 & 59,10 & 31,00 & 47,10 & 0,540 \\
\hline
\end{tabular}

Tabel 3. Efektifitas radiator tipe flat tube kecepatan tinggi dengan variasi waktu

\begin{tabular}{cccccccc}
\hline No & $\begin{array}{c}\text { Time } \\
(\mathbf{S})\end{array}$ & $\begin{array}{c}\text { Air } \\
\text { Velocity } \\
(\mathbf{m} / \mathbf{s})\end{array}$ & $\begin{array}{c}\text { water } \\
\text { in } \\
(\mathbf{C})\end{array}$ & $\begin{array}{c}\text { water } \\
\text { out } \\
(\mathbf{C})\end{array}$ & $\begin{array}{c}\text { Tair } \\
\text { in } \\
(\mathbf{C})\end{array}$ & $\begin{array}{c}\text { T air } \\
\text { out } \\
(\mathbf{C})\end{array}$ & $\begin{array}{c}\text { Efek } \\
\text { tivitas }\end{array}$ \\
\hline $\mathbf{1}$ & 120 & 7,91 & 62,70 & 60,70 & 31,30 & 46,60 & 0,487 \\
\hline $\mathbf{2}$ & 240 & 7,91 & 63,80 & 61,70 & 31,60 & 47,50 & 0,494 \\
\hline $\mathbf{3}$ & 360 & 7,91 & 64,50 & 62,30 & 31,90 & 48,10 & 0,497 \\
\hline $\mathbf{4}$ & 480 & 7,91 & 65,10 & 62,80 & 31,70 & 48,20 & 0,494 \\
\hline $\mathbf{5}$ & 600 & 7,91 & 65,40 & 62,90 & 31,60 & 48,20 & 0,491 \\
\hline
\end{tabular}

Tabel 4. Efektifitas radiator tipe circular cylinder tubepada kecepatan rendah dengan variasi waktu

\begin{tabular}{cccccccc}
\hline No & $\begin{array}{c}\text { Time } \\
(\mathbf{S})\end{array}$ & $\begin{array}{c}\text { Air } \\
\text { Velocity } \\
(\mathbf{m} / \mathbf{s})\end{array}$ & $\begin{array}{c}\text { Tater } \\
\text { in } \\
(\mathbf{C})\end{array}$ & $\begin{array}{c}\text { T } \\
\text { water } \\
\text { out } \\
(\mathbf{C})\end{array}$ & $\begin{array}{c}\text { Tair } \\
\text { in } \\
(\mathbf{C})\end{array}$ & $\begin{array}{c}\text { T air } \\
\text { out } \\
(\mathbf{C})\end{array}$ & $\begin{array}{c}\text { Efek } \\
\text { tivitas }\end{array}$ \\
\hline 1 & 120 & 3,47 & 63,80 & 62,10 & 30,90 & 32,40 & 0,046 \\
\hline 2 & 240 & 3,47 & 65,10 & 63,30 & 30,80 & 32,70 & 0,055 \\
\hline 3 & 360 & 3,47 & 66,10 & 64,00 & 30,80 & 32,90 & 0,059 \\
\hline 4 & 480 & 3,47 & 66,50 & 64,50 & 30,80 & 32,00 & 0,034 \\
\hline 5 & 600 & 3,47 & 66,70 & 65,10 & 30,70 & 32,40 & 0,047 \\
\hline
\end{tabular}

Dari tabel 1 sampai 6 dapat kita analisa bahwa kemampuan pelepasan panas pada radiator jenis circular cylinder tube memiliki kemampuan paling baik pada variasi kecepatan aliran rendah $3.47 \mathrm{~m} / \mathrm{s}$ variasi waktu $360 \mathrm{~s}$ dengan nilai efektifitas 0.59 . Sementara itu secara keseluruhan penurunan temperatur terjadi diantara 0.3-0.4. 
Tabel 5. Efektifitas radiator tipe circular cylinder tube pada kecepatan sedang dengan variasi waktu

\begin{tabular}{cccccccc}
\hline No & $\begin{array}{c}\text { Time } \\
(\mathbf{S})\end{array}$ & $\begin{array}{c}\text { Air } \\
\text { Velocity } \\
(\mathbf{m} / \mathbf{s})\end{array}$ & $\begin{array}{c}\text { T } \\
\text { water } \\
\text { in } \\
(\mathbf{C})\end{array}$ & $\begin{array}{c}\text { T } \\
\text { water } \\
\text { out } \\
(\mathbf{C})\end{array}$ & $\begin{array}{c}\text { Tair } \\
\text { in } \\
(\mathbf{C})\end{array}$ & $\begin{array}{c}\text { T air } \\
\text { out } \\
(\mathbf{C})\end{array}$ & $\begin{array}{c}\text { Efek } \\
\text { tivitas }\end{array}$ \\
\hline 1 & 120 & 6,08 & 66,80 & 64,80 & 31,20 & 32,80 & 0,045 \\
\hline 2 & 240 & 6,08 & 69,10 & 67,90 & 31,10 & 32,70 & 0,042 \\
\hline 3 & 360 & 6,08 & 71,10 & 69,90 & 31,00 & 32,50 & 0,037 \\
\hline 4 & 480 & 6,08 & 73,30 & 71,00 & 31,10 & 32,60 & 0,036 \\
\hline 5 & 600 & 6,08 & 74,30 & 72,70 & 31,10 & 32,80 & 0,039 \\
\hline
\end{tabular}

Tabel 6. Efektifitas radiator tipe circular cylinder tubepada kecepatan tinggi dengan variasi waktu

\begin{tabular}{cccccccc}
\hline No & $\begin{array}{c}\text { Time } \\
(\mathbf{S})\end{array}$ & $\begin{array}{c}\text { Air } \\
\text { Velocity } \\
(\mathbf{m} / \mathbf{s})\end{array}$ & $\begin{array}{c}\text { Tater } \\
\text { in } \\
(\mathbf{C})\end{array}$ & $\begin{array}{c}\text { Tater } \\
\text { out } \\
(\mathbf{C})\end{array}$ & $\begin{array}{c}\text { Tair } \\
\text { in } \\
(\mathbf{C})\end{array}$ & $\begin{array}{c}\text { T air } \\
\text { out } \\
(\mathbf{C})\end{array}$ & $\begin{array}{c}\text { Efek } \\
\text { tivitas }\end{array}$ \\
\hline 1 & 120 & 8,10 & 71,20 & 71,10 & 31,10 & 32,20 & 0,027 \\
\hline 2 & 240 & 8,10 & 73,50 & 73,30 & 31,20 & 33,60 & 0,057 \\
\hline 3 & 360 & 8,10 & 74,70 & 74,60 & 31,20 & 32,20 & 0,023 \\
\hline 4 & 480 & 8,10 & 77,50 & 76,20 & 31,40 & 33,50 & 0,046 \\
\hline 5 & 600 & 8,10 & 78,10 & 77,80 & 31,30 & 32,90 & 0,034 \\
\hline
\end{tabular}

Untuk lebih jelasnya dapat kita perhatikan gambar perbandingan efektifitas antara radiator jenis flat tube (FT) dengan circular cylinder tube(CCT)dibawah ini dengan variasi kecepatan.

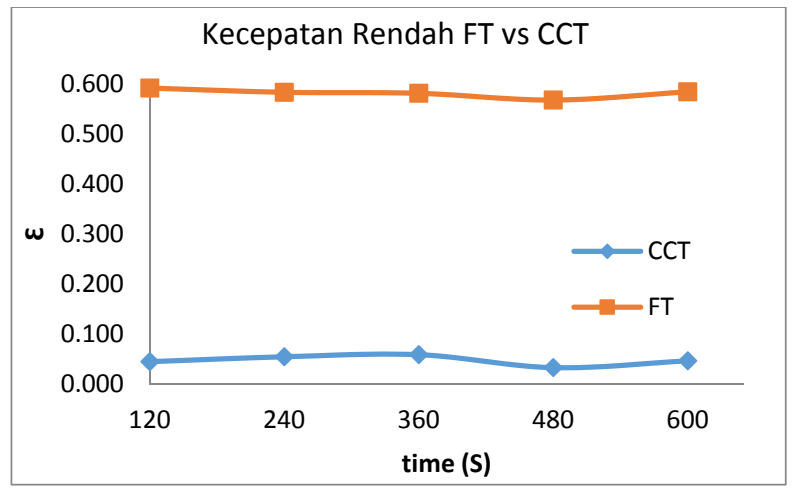

Gambar 6. Perbandingan kemampuan radiator jenis FT vs CCT pada kecepatan rendah

Dari gambar 6, 7 dan 8 terlihat pada semua variasi kecepatan dan waktu radiator jenis flat tube (FT) memiliki efektifitas yang baik dibanding dengan jenis circular cylinder tube (CCT). Hal ini dipengaruhi oleh luasan penampang pelepasan panas dari tipe flat tube (FT) lebih besar dibandingkan dengan circular cylinder tube (CCT). Kontruksi yang membuat kemampuan radiator ini berbeda, karena pada tipe circular cylinder tube
(CCT) secara bentuk sangat tidak aerodinamis dan memiliki gaya hambat yang besar jika dibanding dengan tipe flat tube (FT) sehingga udara yang melalui disirip-sirip radiator terganggu dan tidak maksimal dalam mendinginkan air pendingin.

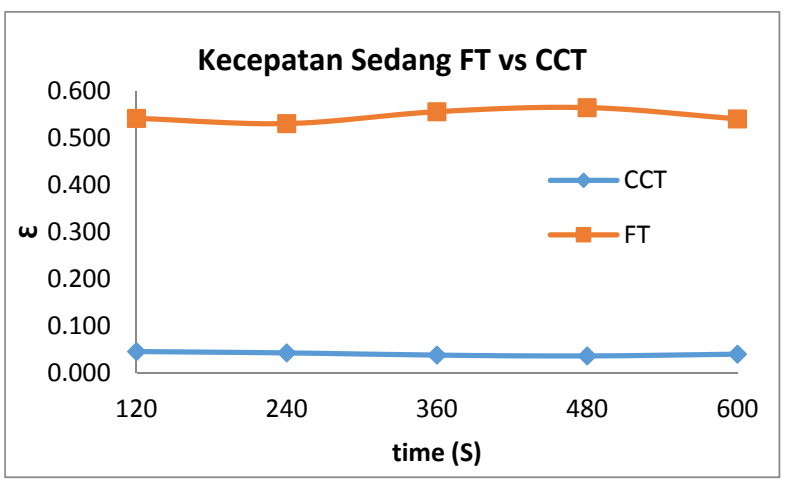

Gambar 7. Perbandingan kemampuan radiator jenis FT vs CCT pada kecepatan sedang

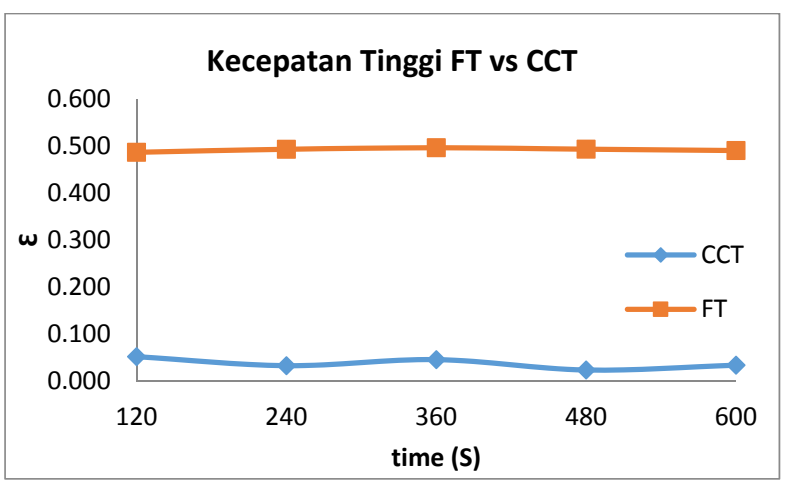

Gambar 8. Perbandingan kemampuan radiator jenis FT vs CCT pada kecepatan tinggi

\section{KESIMPULAN}

Secara keseluruhan dari data hasil penelitian menunjukan bahwa pelepasan yang baik terdapat pada radiator tipe flat tube(FT) dibanding circular cylinder tube(CCT) dan kondisi ini terjadihampir disemua variasi. Kondisi ini disebabkan oleh luasan penampang pelepasan tipe flat tube lebih luas dan laju aliran lebih tinggi karena gaya hambatnya lebih kecil. Gaya hambat kecil diakibatkan oleh kontruksi flat tube (FT) yang lebih tipis dan slim.

\section{DAfTAR Pustaka}

[1] Hidayat, N., Sugiarto, T., Yuvenda, D., (2017). Optimization of Effectiveness in Radiator Straight Fin Type with Flat Tube Angle Variation. International Conference of Applied Science on 
Engineering, Business, Linguistics and Information Technology (ICo-ASCNITech) ISSN : 2598-2532

[2] Adrianto, Dwi, C., Bachtiar, A. (2013), Studi Experimental Pengaruh Perubahan Jenis Radiator terhadap Unjuk Kerja Mesin Sinjai, Jurnal Teknik Pomits Vol 1 No1, hal: 1-6.

[3] Dinaryanto, Okto. (2008). Optimasi Desain Fan Pendingin terhadap Pendingin Radiator, IST AKPRIND Yogyakarta.

[4] Hidayat, Taufiq. (2015), Modifikasi Air Scoop dan Jarak Radiator terhadap Konsumsi Bahan Bakar Bensin, Jurnal Sainstech Politeknik Indonusa Surakarta Vol 1 No 3.

[5] Nazaruddin, Yuliani. (2008), Analisa Debit Aliran Fluida terhadap Efektivitas Radiator pada Engine Mobil Mazda, Sekolah Tinggi Teknologi Pakanbaru.

[6] Holman, J.P. (1998), Perpindahan Kalor, Jakarta: Erlangga.

\section{BiodataPenulis}

Nuzul Hidayat, dilahirkan di Tigo Suku, 16 Januari 1987. Menyelesaikan S1 pada program studi Pendidikan Teknik Otomotif Jurusan Teknik Otomotif FT - UNP Padang tahun 2010 dan pendidikan Pascasarjana (S2) Magister Teknik di jurusan Teknik Mesin Program Pascasarjana ITS Surabaya dengan bidang konsentrasi Rekayasa Konversi Energi pada tahun 2013. Sejak tahun 2013 sampai sekarang menjadi staf pengajar di jurusan Teknik Otomotif FT - UNP.

Ahmad Arif, lahir di Padang Panjang, 27 Februari 1989. Pendidikan S1 di program studi Pendidikan Teknik Otomotif jurusan Teknik Otomotif FT UNP Padang dan lulus tahun 2012. Tahun 2013 2015 melanjutkan pendidikan S2 di program studi Rekayasa Konversi Energi jurusan Teknik Mesin Program Pascasarjana ITS Surabaya. Selanjutnya menjadi staf pengajar di Jurusan Teknik Otomotif FT - UNP sejak tahun 2015 sampai sekarang.

Martias, lahir di Ladang Lawas, 1 Agustus 1964 Sarjana Pendidikan di Jurusan Teknik Otomotif FT - UNP. Memperoleh gelar Magister Teknik di program studi Pendidikan Kejuruan jurusan Pendidikan Teknik Kejuruan Program Pascasarjana UNP Padang. Staf pengajar di Jurusan Teknik Otomotif FT - UNP sampai sekarang. 